\title{
Rural Areas with Seasonal Homes Hit Hard by COVID-19
}

Jessica A. Carson

UPDATE (4-29-20)—Case data through April 27, 2020 indicate that the gap between rural counties with higher and lower shares of seasonal housing has essentially closed. While cases per 100,000 have continued to rise in both kinds of places, the shrinking gap is largely attributable to rising rates in rural places with less seasonal housing, as fewer communities are left untouched by COVID-19. Urban cases per 100,000 outstripped both kinds of rural counties as of April 9, 2020.

A $\mathrm{s}$ the pandemic escalates, rural counties with high shares of seasonally vacant housing are seeing higher rates of COVID-19 cases than either urban or other rural areas. In the nation's 199 rural counties where seasonal housing accounts for 25 percent or more of all housing units, average cases per 100,000 are more than twice as high as in other rural counties and 15 percent higher than in urban areas as of April 5 (Figure 1). This is consistent with anecdotal reports of hot spots in popular vacation locations as visitors, including some who are unknowingly infected, exit urban areas attempting to socially distance at second homes and seasonal rental properties. There are, however, several possible explanations for the higher prevalence of cases including differences in the level of testing and the higher median age seen in these areas.

\section{FIGURE 1. MEAN COVID-19 DIAGNOSES PER 100,000 BY COUNTY CHARACTERISTICS}

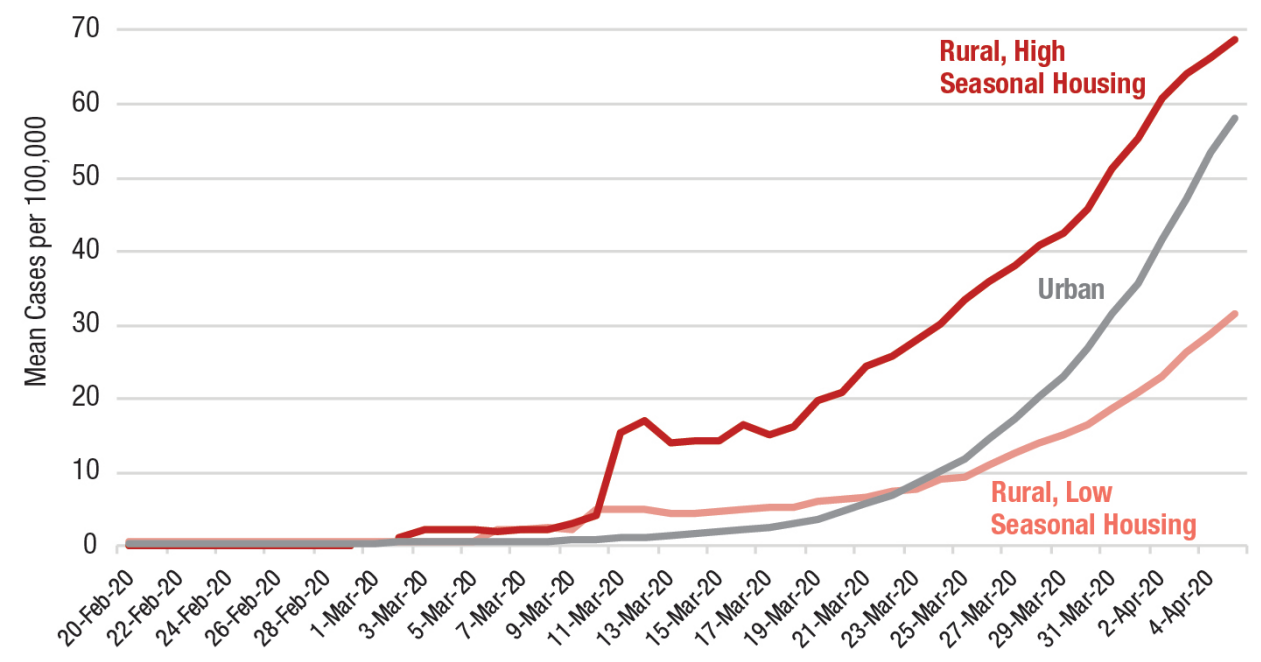

Notes: "High" share of seasonal housing is defined as 25 percent or more of all housing units are for seasonal, recreational, or occasional use. Rural-urban designation uses the Economic Research Service's (2013) Rural Urban Continuum Codes, the most recent available. Horizontal axis begins on February 20,2020, the earliest reported diagnosis in a rural county. Source: Author's calculation using data from The New York Times, U.S. Census Bureau's American Community Survey (2018 5-year estimates), and ERS Rural Urban Continuum Codes. NYT case data downloaded 4/6/20, covering through 4/5/20.

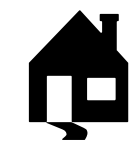

In rural counties with high shares of seasonal housing, average cases of COVID-19 per 100,000 are twice as high as in other rural places.

\section{About the Author}

Jess Carson is a research assistant professor with the Vulnerable Families Research Program at the Carsey School of Public Policy. Since joining Carsey in 2010, she has studied poverty, work, and the social safety net, including policies and programs that support low-income workers like affordable health insurance, food assistance programs, and quality child care.

\section{See Related Publications at carsey.unh.edu \\ - "Not very many options for the people who are working here": Rural Housing Challenges Through the Lens of Two New England Communities (November 2017)}

